\title{
ICT and Social Work: a Question of Identities?
}

\author{
Véronique Laurent \\ Cellule Interdisciplinaire de Technology Assessement \\ University of Namur, Belgium \\ vla@info.fundp.ac.be
}

\begin{abstract}
Computers and Information and Communication Technologies (ICT) have become, nowadays, part of the daily work environment of numerous enterprises and organizations. Social services organizations are concerned by those technological changes affecting various fields like, for instance, social help management, contact with public, communication between social workers, relationships with authorities. The integration of technologies in organizations generally raises many questions. Those questions concern worker's use, perception, trust and appropriation of ICT. Our paper will focus on a recent empirical research about computerization in Belgian Public Social Action Services (CPAS) undertaken by the University of Namur. The central issue raised in this research regards the potential impact of ICT on the professional identity of the social workers, questioning a potential cultural shock between new visions of social work endorsed by ICT programs and patterns and the traditional ones at work amongst the social workers. Using identity theory, structural approach of computerization and empirical data, we will try to analyze this central issue following different steps. This issue is very critical when considering that professional identity has crucial impact regarding the way social workers operate and the relationships they have with public concerned.
\end{abstract}

\section{Introduction}

Main objective of this contribution is to relate the potential impact of ICT on the professional identity of the social workers in CPAS. Using empirical data and an identity perspective, we will study the potential impact of ICT on the professional identity of the social workers, questioning a potential cultural shock between new visions of social work endorsed by ICT programs and patterns and the traditional ones at work among social workers.

This issue is very critical when considering that professional identity has crucial impact regarding the way social workers operate and the relationships they have with public concerned.

In a first part, we will describe universes and evolutions of poverty, social work and CPAS. Secondly, we will analyze the integration of technologies in those

Please use the following format when citing this chapter:

Laurent, V., 2008, in IFIP International Federation for Information Processing, Volume 262; The Future of Identity in the Information Society; Simone Fischer-Hübner, Penny Duquenoy, Albin Zuccato, Leonardo Martucci; (Boston: Springer), pp. 375-386. 
services, according to the results we have collected about use and perception of ICT by workers. In a third part, we will confront the different dimensions of technology and social care, especially as far as social workers are concerned. Finally, we will conclude our paper with some practical recommendations questions for a more successful adaptation between frameworks of ICT and CPAS. We will also purpose some additional perspectives to our research.

We will mainly focus on workers and their perception of the situation. Detailed impacts of ICT like organizational changes and transformations in the job qualifications will not be covered here. Those concepts are further investigated in our book [1] and in literature about computer story and impacts [2].

\section{Research methodology and identity perspective}

\subsection{Computerization in Belgian Public Action Services}

CPAS exist are responsible of social help of citizens in each municipality (589 in Belgium). Each service has an independent juridical status, but must enforce everyday different decisions and laws coming from various levels of power (Belgian Federal State, regions, provinces, municipalities,...) [3].

Belgian Public Action Services are concerned about computerization. Indeed, those are frequently in contact with ICT, generally used in various fields like, for instance, communication with users, workers and organizations, human resources and management, secretarial work, treatments of users and of social documents, and accountancy. Computer firms, subsidiary powers and public authorities have developed the used applications. Since the $1^{\text {st }}$ January 2006, CPAS have been constrained to use ICT, due to their obligation to be connected to a national computerized network of data-bank concerning users, so called the social security crossroad.

At the end of the year 2005, our research team was contacted by a delegation of CPAS from Wallonia ${ }^{1}$ to undertake a holistic survey in order to identify the new challenges of computerization in their sector (262 CPAS) [4]. Our group was composed of two sociologists, one psychologist and three jurists.

Using an interdisciplinary point of view, we have tried to answer to new challenging questions concerning the relationship between computerization and social work. How are ICT used and perceived in CPAS? What are the impacts of using ICT in work and identity of social workers? Are the users of social services concerned by

${ }^{1}$ Belgium is divided into three regions and three different language speaking communities. The three regions are Wallonia, Brussels and Flanders. The three communities are the French speaking community, the Flemish speaking community and the German-speaking community. The link http://www.belgium.be is an useful starting point to get to know Belgium. 
the digital divide? What can be the advantages of using ICT for people helped by social services? What are the legal challenges concerning ICT?

Our research was made from October 2005 to May 2007. Our methodology has been qualitative and quantitative. To collect our empirical data, we have, in a first step, made several visits and interviews in Belgian Public Action Services. In a second step, from February to March 2006, we have undertaken a large survey, sending a questionnaire to each person in charge of a CPAS ${ }^{2}$ [4]. This survey has been conceived in close relationship with workers. In conclusion of our research, we have written a book, presenting our results and practical recommendations for the social work sector, scientists and public authorities [1].

\subsection{Our identity perspective}

One of the focus of this paper does concern professional identity of social workers. The concept of professional identity is wide and different frames of analysis can be adopted. Among those ones, we have chosen to adopt the theories of Henri Tajfel and John Turner about social identity [5].

In everyday life, each individual meets different social groups, deliberately chosen or not. A family, a sports group, a working group, a country can be some examples of different group constituting an individual's social identity. Following these authors, social identity will be understood as "a part of individual's self-concept which derives from his knowledge of his membership of a social group (or groups) together with the value and emotional significance attached to that membership" [5].

For Tajfel and Turner, social identity is not necessary linked to objective properties. You can, for instance, feel yourself belonging to the black community without having any black skin. You can also use intensively technologies without feeling like belonging to a group of ICT users. On the contrary, an individual's social identity is represented by his affective attachment to groups or social categories he wants to be connected.

The description of "what "is" a group" by an individual includes a range of between one to three components: "a cognitive component in the sense of knowledge that one belongs to a group; an evaluative one, in the sense that the notion of the group and/or of one's membership of it may have a positive or a negative value connotation"; and an emotional component "in the sense that cognitive and evaluative aspects of the group and one's membership of it may be accompanied by emotions (such as love or hatred, like or dislike) directed towards one's own group and towards others which stand in certain relation to it." [5]. How is technology integrated in professional identity of workers in social services? In our paper, we will examine and analyze those three above mentioned dimensions (cognitive, evaluative

2 The population of our survey was persons in charge of CPAS in CPAS from wallonia. We received 131 answers: $50 \%$ of our population. However, only 126 questionnaires $(48 \%$ of the Walloon CPAS) could be used within the framework of this study. Five questionnaires were not exploitable, fault of being correctly filled. More information about our methodology is in our survey report [4] and our book [1]. 
and emotional) according to the results we have collected in our research about use and perception of ICT.

\section{The universe of social work and its evolution}

Having specified our research framework and our identity perspective, we are going to describe and to precise the general context that surrounds the CPAS in order to better understand the mutual interactions between ICT and social action. Poverty, social work and Belgian Social Services have evolved in accordance with their times. We can detail this evolution in four main points.

\subsection{From social care to social action}

After their creation, in the seventies, public social services were practicing 'social care', granting care and a minimal income to people in need. Nowadays, the situation has changed. This concept of "social care" has disappeared, leaving space to the concept of "social integration" (1990), and now, to the concept of "social action" (2002). In this new context, it is increasingly required from people to use their own abilities to benefit from the social care and help from CPAS. Users are given responsibilities to change their position in society.

\subsection{A greater diversification of social care activities}

A second change regarding CPAS has been the greater diversification of social care activities since their creation. Indeed, due to the evolution of poverty and the changes in law, CPAS have been attributed additional and diversified missions: housing, debts mediation, management of old people's housing, family services, minor's protection, catering, ... Those tasks are now added to the three basic missions of a CPAS: social assistance, medical care and social and medical activities.

\subsection{Areater diversification of benefactors}

A third trend is the greater diversification of benefactors of CPAS due to economic factors. A more diversified range of people from various background could, one day, be in need and then be confronted with social action. Citizen being not in conditions to receive financial help from CPAS can also benefit from their services, for example for information, old people's housing or family services.

\subsection{A bigger interconnection with other actors}

To conclude, important actors surrounding social action are more diversified. Indeed, CPAS are being increasingly interconnected with other actors of economic and social 
life like public authorities, associations, fundings authorities, companies, ... Those are also increasingly working in cooperation.

\section{The identity of social workers}

In order to better understand the mutual interactions between ICT and social action, we are now going to analyze the identity of social workers. Methods and conceptions of social work in CPAS have been extended. Sociologists Guy Bajoit and Abraham Franssen [7] (1997-1998) have developed a typology regarding the four different profiles at work in social working. This typology has emerged from a research with social workers concerning the ways of perceiving their own role (see Fig. 1).

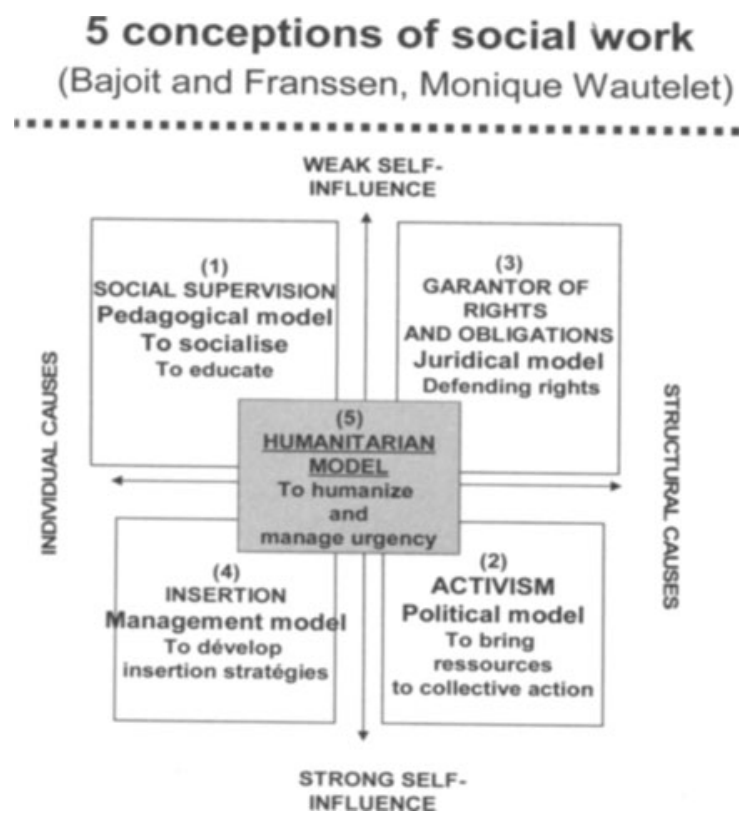

Fig 1. Five conceptions of social work

This typology is the result of crossing of two main axes. The first refers to the causes of marginality, perceived like being linked to individual causes or to structural causes. The second axis refers to the capacity of individuals to change their situation. A person can be seen like having a strong influence on his/her present condition (empowerment) or like having a weak influence on his/her own marginality. Four identity models of the social worker, being four ways of perceiving their own role, exist around these two axes.

(1) Pedagogical model is based on charity and on rehabilitation. Benefactors are perceived as responsible of their own precariousness and as deprived 
of abilities to improve their situation. Social worker is an agent of social control whose mission is to guarantee the respect of social norms.

(2) Political model is related to the conception of social work in the seventies. Within this framework, the role of the social worker has become an agent of social transformation. Poverty is considered as a result of social domination. Social workers have adopted the idea that it is possible to fight against poverty while being organized collectively, speaking or being an actor in society. Benefactors are perceived as exploited or excluded. Social worker has a role of militant, bringing resources to collective action.

(3) In the juridical model, benefactors are perceived as precarious due to structural causes (unemployment, diseases,...). Users are seen like irresponsible victims of a system, having right to an institutional solidarity. Social worker is regarded itself as a guarantor of rights and duties of benefactors.

(4) To conclude, the management model perceives benefactors as responsible for their own situation while having obligation to be integrated in society. The role of social workers is to support autonomy of the benefactors while being agents of social control. A social worker has a role of social manager.

In addition of those four models, Monique Wautelet, a Belgian social assistant, has also worked on that subject and has created a fifth model, at the crossroad of the other: the humanitarian model [8]. This identity model is acts above all on the effects of a problem, without putting questions about its causes. The user is perceived like being in poverty and the role of social worker is to humanize and manage urgency.

Following those models, the identity of "social workers", through its cognitive (what social workers know about their professional group), evaluative (positive and negative value connotation of the group) and emotional components (emotions directed towards the group) can be perceived in different ways. We have observed the existence of those five models in CPAS of our research.

\section{The place of ICT in social work}

Due to national obligation to be connected to a computerized network, and particularly to the national social security crossroad, each CPAS is generally well equipped in ICT (PC, servers and internet connexions). Our central question is how ICT can affect the ways or working in CPAS and particularly the professional identities of the social workers in their three layers quoted above: cognitive, evaluative and emotional one. 


\subsection{Cognitive component of ICT}

Workers have two spontaneous opposite knowing of computerization. On one hand, computerization is viewed as a tool, helpful for social action with different benefits: to gain time, increase speed in the treatment of documents, be more efficient, ... On the other hand, computerization is viewed as a barrier for social action. In both cases, ICT are viewed as mandatory, requiring new skills and qualifications to use it and to integrate it in their every day work.

\subsection{Evaluative component of ICT}

The assessment of CPAS workers over computerization is overall rather positive, even if some risks regarding the quality of the social action are pointed out by the social workers. [4].

The efficiency of ICT has been mainly underlined. $96 \%$ of respondents agree or totally agree with the fact that computerization makes their work more efficient. $73 \%$ have the same position on the fact that ICT improves the internal communication and facilitates the exchanges of information. $74 \%$ agree or completely agree with the fact that ICT shortens the retrieval of documents and $84 \%$ think that ICT increases the capacity of action and resolution of problems by a better access of each worker to information.

Risks related to computerization are generally understated by CPAS. Indeed, only $22 \%$ agree or completely agree with the fact that ICT implies more control on the work of employees. $15 \%$ adopt the same position regarding the risk related to the decreasing of social skills and knowledge. Though, $36 \%$ consider that burdens social work since ICT programs are often viewed as too complex, needing long time of adaptation. The fact that ICT programs are numerous without any coordination between them increases this complexity and obliges to re-key the same data several times. Finally, for $26 \%$, ICT decrease the freedom of the employees in the way they can manage social cases and related documents.

Some fears about ICT have been underlined in CPAS. Indeed, nearly 50\% agree or completely agree with the fact that use of computer decreases the proximity between social worker and concerned public. $74 \%$ have the same opinion regarding the fact that data processing does not improve the relation between social workers and people being given social care.

To conclude, the normative feature of computerization is underlined since $82 \%$ consider as normal that, in our era of E-government, circulars or law related to them are sent via Internet.

\subsection{Emotional component of ICT}

Those rather positive opinions regarding ICT contrast strongly with the feeling shared by all the social workers who perceive ICT more as a mandatory external requirement than as an internal choice supported by a true process of negotiation and 
appropriation. This feeling can be better understood when knowing that most of the ICT programs at use in CPAS have been imposed by the various public authorities funding and surrounding the CPAS. This feeling is reinforced by the little mean at disposal to really appropriate those devices. Less than one third of the surveyed CPAS benefits from the presence of computer scientists to help them in their ICT appropriation and management (there were 46 computer scientists for $126 \mathrm{CPAS}$ ). Both feeling of obligation and lack of qualified people explain also that only $48 \%$ have developed a true ICT policy, which again reinforced their feeling of an 'external dictator' regarding their technological destiny [4].

\subsection{A contrasted image of computerization}

According to the survey, all the CPAS are not on the same level regarding their use and their perception of ICT. On the contrary, computerization seems better fit with certain professional profiles identified in the typology presented before.

Two profiles seem better match with the ICT's purposes and requirements. It is first of all the social management profiles motivated by goals of rationalization and efficiency both compatible with the aims of ICT. It is also the humanitarian profile stimulated by the social emergency and for whom ICT bring an image of rapidity and efficiency. In these two cases, computerization seems to be 'the tool of the situation', facilitating a more rational management and helping to react quickly to social emergencies.

On the contrary, technologies seems to be less in accordance with profiles like the pedagogical (1) and the militant one (2), based on personal and close relationships with the public aiming at empowering people and at fighting against social exclusion.

\section{ICTs and social work : two opposite logics?}

To explain the cautious assessment made by social workers on their ICT surroundings, one could make the hypothesis that a cultural shock exists between the initial logics that support the social work, on one hand, and, on the other, those at work with the computerization ${ }^{3}$.

Comparing those two logics can help to understand difficulties encountered by some social workers regarding the integration of these news ways of working in their every day life. It can also explain a shift at work in some CPAS between those who adopt ICT and those who are left behind. Finally, it also explain some political games at work in the CPAS between clerical workers and social workers, the first ones gaining in power due to their larger involvement into ICT's matter. All those observations seem to lead to a certain digital divide into the CPAS world.

3 The components of those logics have been created on basis of literature, observations, interviews, and our survey's results. 
Table 1. Comparison between frameworks of ICT and of social work

\begin{tabular}{|l|l|}
\hline \multicolumn{1}{|c|}{ Logics of computerization } & \multicolumn{1}{c|}{ Logics of social work } \\
\hline $\begin{array}{l}\text { Standardization - rationalization of social } \\
\text { care with the use of formatted programs or } \\
\text { applications }\end{array}$ & $\begin{array}{l}\text { Personalization of practices - case by case } \\
\text { work }\end{array}$ \\
\hline $\begin{array}{l}\text { Information sharing due to computer } \\
\text { servors, Internet, e-mail, ... }\end{array}$ & $\begin{array}{l}\text { Confidential work - each social worker has his } \\
\text { own way of working }\end{array}$ \\
\hline Written tradition - bureaucratization & Oral and proximity tradition \\
\hline Speed - efficiency & Slow work with users \\
\hline $\begin{array}{l}\text { Quantitative judgments and global approach } \\
\text { of reality (statistics) }\end{array}$ & $\begin{array}{l}\text { Qualitative judgments (more individualized } \\
\text { approach) }\end{array}$ \\
\hline
\end{tabular}

\section{$7 \quad$ A limited cultural shock?}

However, the mutual opposition of technology and social services is limited. Our epistemological approach refuses to adopt a strictly determinist position, considering technology "as an objective external force that would have (relatively) deterministic impacts on organizational properties such as structure." [9]. On the contrary, we advocate for "a structurational model of technology" [9]. Our model of reference is Giddens'theory of structuration [10]: "The theory of structuration recognizes that human actions are enabled and constrained by structures, yet that these structures are the result of previous actions" [9]. Computerization is part of structures, having influences and being influenced by human workers or human actions.

The introduction of ICT in an organization is not sufficient in itself to change professional practices. This appropriation of technology has two conditions. It "requires not only that the receiving ground has the necessary means to assimilate and use the object, but also a need of the object to answer questions or a difficulty which arises, even implicitly" [11].

Workers can also manifest strategic attitudes of resistance. Generally, professionals of a sector cannot be completely constrained by ICT. They always have the freedom and possibilities of playing with the rules.

Eventually, computerization has its limits. It is, therefore, far from being extended to all the features of work in CPAS, and largely, of social work. Indeed, most of those workers use daily relational, listening and empathy qualities with their users. ICT are definitely not sufficient to replace the practices of social workers by machines.... 


\section{Conclusion, practical recommendations and additional points of view}

\subsection{Conclusion}

Main objective of this contribution was to relate the potential impact of ICT on the professional identity of the social workers in CPAS.

As underlined before, CPAS rather perceive computerization as an obligation than as a real project. The fast rhythm imposed by their public authorities for their computerization has not given time to adapt themselves to ICT, nor has it provided them with a sound policy to appropriate ICT to their identity. Meanwhile, our analysis shows that these difficulties are unequally perceived by CPAS, according to their means and their resources, but mostly according to their perception of social action.

Computerization seems to fit rather well with professional identity perceiving social action as a matter of efficiency and of emergency for which it is necessary to react with speed and effectiveness (like in the management and the humanitarian profiles). On the contrary, technologies seems to be less in accordance with professional identities for which social work is first of all a question of proximity, of personalized process of caring and of defense of excluded people (like in the political and the humanitarian profiles). For those professional identities, there exist a bigger 'cultural shock' between logics of ICT and logics of social work. Indeed, the bureaucratization related to ICT appears as incompatible with the personalized process they deploy with excluded people.

\subsection{Recommendations}

Many adjustments and dialogues are possible to avoid 'a marriage of convenience' between CPAS and ICT and to facilitate the appropriation of ICT by those services. However, many efforts have to be done to foster this appropriation. First of all, it seems that the traditional model of ICT imposition endorsed by the related public authorities should gain in maturity and effectiveness by a better consultation and a true negotiation with the concerned CPAS. On the other hand, CPAS should be encouraged to develop ICT policies regarding their needs, theirs projects and their capacities. To conclude, ICT appropriation is a training matter and, in this domain, a sound effort should be done in the learning programs that support the social workers education.

Nevertheless, the major change has to expect from the community of CPAS acting as a single demanding player since most of them share the same difficulties and constraints. This goes through three main recommendations:

- Our first recommendation would be to create a regional platform, federating CPAS. It would be an intermediary between CPAS, public authorities and computer companies. It could help social center to 
negotiate computer applications, and the development of their computerization.

- A second recommendation is to implement communities of practices for CPAS. Those communities would bring further solidarity between social services. CPAS could share their experience, computer perceptions and resources. Those communities could also allow CPAS to define common computer policy and could teach the employees the new challenges of computerization (use and maintenance of ICT, ethical and legal perspectives, ...)

- Our third recommendation would be to create an external observatory for the computerization of CPAS. This observatory could report to public authorities the problems and lacks of means of CPAS concerning their computerization process. Public authorities could adapt their policy accordingly.

Acting as a community can give a chance to each CPAS to better master its ICT policy and to each of the concerned social worker to move from an ICT obligation to an ICT appropriate project.

\subsection{Towards further researches?}

Each research has unfortunately its own limits! Different additional perspectives could be an interesting complement to our research.

In a first time, it could be very interesting to compare our computerization research's results with those of social services in other countries or in other cultures. A comparison between ICT's integration in CPAS and in other associations or public organisations (hospitals, public administrations or municipalities, ...) could also be useful. Secondly, a qualitative and quantitative analyse of benefactor's perceptions about computerisation of work in social services could be an enriching view for our study. Those perceptions could be added to another analyze: professional identity of other actors surrounding CPAS: public authorities, associations, subsidiary powers, companies, Third, our results need to be frequently updated. A longitudinal study would give interesting data to observe evolutions and changes in social sector.

Computers and ICT are evolving and increasing in social professions. The central message of this paper is that their deployment is not a fate. Human workers always have the possibility to be actors of their computerization. Therefore, our contribution could also be interesting for other kinds of organizations.

\section{Acknowledgments}

I would like to thank my research team: Claire Lobet-Maris, Françoise Navarre, Cedric Burton, Yves Poullet and Philippe Versailles. I also thank also my colleagues of the CITA and the summer school participants I have met in Karlstad for the 
interesting discussions we had. Their contributions have been very useful for the redaction of this article.

\section{References}

1. C. Burton, V. Laurent, F. Navarre, Y. Poullet, and P. Versailles, Quand l'informatique rencontre l'action sociale... Regards pluridisciplinaires sur l'informatisation des CPAS (Presses universitaires de Namur, Namur, 2007).

2. J. Agar, The Government Machine: A Revolutionary History of the Computer (MIT Press, Cambridge, 2003).

3. J.M Berger, Mémento des CPAS (Kluwer, Bruxelles, 2004).

4. C. Burton, V. Laurent, C. Lobet-Maris, F. Navarre and Y. Poullet, L'informatisation des CPAS, une informatique plurielle au service de l'action sociale, Rapport de résultats du questionnaire préparatoire au Colloque des Secrétaires de CPAS (Herbeumont, April 2006, http://www.fundp.ac.be/pdf/publications/57376.pdf).

5. H. Tajfel (dir.), Differentiation between social groups, studies of the social psychology of intergroup relations, (Cambridge, Academic Press, 1978), p 28.

6. R. Castel, Du travail social à la gestion sociale du non travail, Revue Esprit, (1998), pp. 2845.

7. G. Bajoit, A. Franssen, Le métier d'assistant social, Travailler le social, n¹7, 1997-1998, pp 36-70.

8. M. Wautelet, Le métier de travailleur social en CPAS : aujourd'hui et demain, lecture at the Carrefours du Printemps de la Fédération des CPAS de l'Union des Villes et des Communes de Wallonie (2004, http://www.fewasc.be/pages/news/news13.htm).

9. W. Orlikowski, The duality of technology: rethinking the concept of technology in organizations, Organisation Science, (vol 3, num 3, 1992), pp. 398-427, (p.399-403-404).

10. A. Giddens, The constitution of society: Outline of the theory of structuration (Oxford, Polity Press, 1984).

11. G. Chevalier, Les services sociaux à l'épreuve de l'informatique (European Science Foundation, Issy-les-Moulineaux, 2000), p. 95. 